This item was submitted to Loughborough's Research Repository by the author.

Items in Figshare are protected by copyright, with all rights reserved, unless otherwise indicated.

\title{
Impact of corporate credit scoring on construction contractors in China
}

PLEASE CITE THE PUBLISHED VERSION

https://doi.org/10.1061/(asce)co.1943-7862.0001631

\section{PUBLISHER}

(C) American Society of Civil Engineers (ASCE)

\section{VERSION}

AM (Accepted Manuscript)

\section{PUBLISHER STATEMENT}

This work is made available according to the conditions of the Creative Commons Attribution-NonCommercialNoDerivatives 4.0 International (CC BY-NC-ND 4.0) licence. Full details of this licence are available at: https://creativecommons.org/licenses/by-nc-nd/4.0/

\section{LICENCE}

CC BY-NC-ND 4.0

\section{REPOSITORY RECORD}

Xiong, Bo, Martin Skitmore, Paul Xia, Pablo Ballesteros-Perez, Kunhui Ye, and Xiaoling Zhang. 2019. "Impact of Corporate Credit Scoring on Construction Contractors in China". figshare. https://hdl.handle.net/2134/36765. 
This is a post-refereeing version of a manuscript published by ASCE.

Please, in order to cite this paper properly:

Xiong, B., Skitmore, M., Xia, P., Ballesteros-Pérez, P., Ye, K., Zhang, X. (2019) “Impact of Corporate Credit Scoring on Construction Contractors in China." Journal of

Construction Engineering and Management, 145(4), 05019002.

https://doi.org/10.1061/(ASCE)CO.1943-7862.0001631

The authors recommend going to the publisher's website in order to access the full paper.

If this paper helped you somehow in your research, feel free to cite it. 


\section{Impact of corporate credit scoring on construction contractors:}

\section{A China study}

Bo Xiong, Ph.D. ${ }^{1}$; Martin Skitmore, Ph.D. ${ }^{2}$; Paul Xia, Ph.D. ${ }^{3}$;

Abstract

In an attempt to enhance the trustworthiness of contractors and reduce corruption, the

China Government has launched a construction contractor credit scoring (CCCS) scheme in

Beijing for evaluating the compliance and integrity of contractors registered in the construction market. The contribution of this paper to the Body of Knowledge is to analyze how the incorporation of CCCS may affect general contractors' present and future competitiveness through a case study in China. The paper analyzes the procurement of 158 building projects tendered in Beijing, involving 2071 local general contractors active in the market. The results show that (1) the contractors' CCCS scores are important for being awarded large and mega project contracts; (2) $C C C S$ scores have a generally positive effect on future corporate financial income; and (3) that, contrary to expectations, the policy does not increase the CCCS of companies. Finally, it is observed how the changing trend in contractors' $C C C S$ scores is highly

\footnotetext{
${ }^{1}$ Research associate, Luohu Urban Renewal Authority, China, peterxiongbobo@163.com

2 Professor, School of Civil Eng. and Built Env., Queensland Univ. of Tech. (QUT), Australia; Faculty of Computing, Engineering and the Built Environment, Birmingham City University, Birmingham, UK. rm.skitmore@qut.edu.au

${ }^{3}$ Associate Prof., School of Civil Eng. and Built Env., Queensland Univ. of Tech. (QUT), Australia; School of civil and hydraulic engineering, Hefei University of Technology, China. paul.xia@qut.edu.au

${ }^{4 *}$ Corresponding author: Senior Lecturer, School of Archit., Build. and Civil Eng., Loughborough Univ., United Kingdom, p.ballesteros-perez@lboro.ac.uk

${ }^{5}$ Professor, School of Construction Management and Real Estate, Chongqing University, China, Kunhui.Ye@Gmail.com

${ }^{6}$ Associate Prof., Dept. of Pub. Policy, City Univ. of Hong Kong, China, xiaoling.zhang@cityu.edu.hk
} 
17 correlated with their initial values (the scores of higher CCCS scoring companies increase faster on average than other companies). Final remarks concern ways to better implement $C C C S$ schemes in the future and avoid the potential risks involved in their use.

21 Keywords: Credit scoring, project procurement, construction contractor, policy evaluation, 22 China.

Introduction

Governments worldwide consume many resources, goods and services, and governmental expenditure accounts for a large portion of the Gross Domestic Product (GDP).

27 Being ethical and transparent as well as pursuing principles such as efficiency, competition, value for money (VFM) and industrial development is the key for successful public procurement (Raymond 2008). However, corruption and collusion are serious problems in many developing countries due to poverty and weak law enforcement (Nwabuzor 2005).

To help improve the situation in Beijing, a construction contractor credit scoring (CCCS) scheme evaluating the credibility and compliance of construction contractors was firstly launched by the local government in 2013. However, even though the Beijing CCCS scheme has been gradually adopted by other provincial governments in China, its impact on contractor selection and project procurement has not yet been tested empirically. As is common practice in China today, phased policy initiation and closely evaluated pilot schemes are to be conducted before large-scale implementation to reduce risks and improve further implementations 
38 (Swanson \& Bhadwal 2009). It is particularly important, therefore, to compare the policy goals with the results actually achieved (Nakamura 1987).

Towards this end, this article aims to gauge the impact of $C C C S$ on project procurement and construction contractors at the initial stages of implementation. The development of construction project procurement in China is firstly reviewed and the recently incorporated scores in construction project procurement, the process of developing and applying this new public policy is next reviewed. The research questions to be answered are then posed: How do the CCCS scores affect contract competition? What is the relationship between the new policy applications in other countries.

\section{Literature Review}

\section{Public Procurement Policy}

The procurement stage of public projects is the most commonly affected by unethical and illicit practices. This has led to calls for improved procurement practices in both developed and developing countries (Tow and Loosemore 2009). As an antidote to these problems, alternative ranking and scoring rules, including the average bid method (Ioannou and Leu 1993) and below-average bid method (Ioannou \& Awwad 2010), have been increasingly applied in some countries (see Ballesteros-Pérez et al. 2015a for a recent and comprehensive taxonomy). 
In addition to price, it is often advocated that other issues including schedule, safety, and management ability should be assessed in contractor selection as well as prequalification

61 (e.g., Hatush and Skitmore 1998). Likewise, appropriate measures of corporate credit reflected in corporate compliance and previous performance on projects and contract implementation are said to be critical (Drew and Skitmore 1992; Shen and Song 1998; Shen et al. 2004), this being the reason why multi-attribute tender evaluation has been gaining popularity in recent years (Ye et al. 2012).

It is also important that public procurement should be concerned with issues affecting disadvantaged groups. For example, Walker and Preuss (2008) examined opportunities for enhancing sustainability in supply chains by sourcing from small and medium-sized enterprises (SMEs) in health care and local government. This is important because "SMEs are more innovative and come up with new products, but are often taken over by big suppliers who end up deciding what you should have" (Walker and Preuss 2008, p20).

In the UK, for example, the Government Sustainable Development Strategy requires local governments to embed sustainable development considerations into decisions on governmental spending and foster some changes on public procurement in local government (Preuss 2009). The priorities of public procurement should therefore be developed based on needs within the political, economic, social, technological, environmental, and legal background (e.g., Bekkers et al. 2011). Integrity and accountability for the use of public money needs to be emphasized as well as the expectation of high levels of credibility among participating companies and governmental officials. The policy examined in this study is an attempt at incorporating such credibility into public procurement policy. 


\section{The Situation in China}

Since joining the World Trade Organization in 2001, there has been a wide expectation

that China will assume much more responsibility in the international market and maintain improved ethical norms in both Chinese society and business collaborators worldwide (Tam 2002). In pursuance of this, many administrative authorities have issued policies and regulations to assure the compliance of companies. For example, China's 2005 Company Law (Lin 2010) legislates that companies should respect laws, social morality and trade honesty, as well as assuming an exemplary level of social responsibility. Subsequently, in 2008, the State Council issued the Guidelines on Corporate Social Responsibility Fulfilment for State-Owned Enterprises in China, requiring all state-owned enterprises to actively guarantee social responsibility in terms of awareness, implementation, business credits, prudent use of resources and environmental protection.

Within this context, Chinese construction contractors are becoming increasingly aware of the importance of corporate social responsibility and the nexus between corporate social performance and financial performance (Xiong et al. 2016). However, China's construction industry has been dogged by scandals and tragedies for a long time. These have been mostly caused by low trade credit and poor quality construction work (Shaw 1997). of resources and energy, generally involving poor working conditions, frequent conflicts, and significantly negative impacts on the environment (Fenn et al. 1997; Lu and Tam 2013; Shen 
and Tam 2002). There are also more than 40 million immigrant construction workers in China, many of whom are not paid on time (CBS 2013); this, along with China's other structural problems and below-standard worker safety, has also contributed to a large number of casualties in the construction industry (Liu et al. 2011). The prevalence of corruption and collusive bidding are also another two well-known problems (Xiao 2014).

Competitive bidding has been used in China since the early 1980s (Lai et al. 1998). Along with China's economic transition to a market economy, the procurement of construction projects has changed from a negotiated awarding procedure, where only state-owned contractors were entitled to participate, to an open competitive tendering scheme (Shen and Song 1998). As defined in public procurement regulations by the Chinese Ministry of Finance (MOF 2004) and construction tender regulations issued by the National Development and Reform Commission (NDRC 2003), the procedures for construction project procurement generally comprise tender notice (invitation), submission, opening, evaluation, and selection. specialist contractors and labor contractors (MOC 2015). For general contractors, there is an additional grade of "Excellence" in addition to Grade 1, Grade 2, and Grade 3. Such grading reflects corporate capital, size and previous performance record (Shen et al. 2004) and is only required for tender notification and pre-qualification.

Competition intensity in the national construction project market is very high (Ye et al. 2008). Multi-criteria tender assessment methods are available in contractor selection, with bid evaluation used to measure whether bidders' proposals meet client expectations. According to a survey by Shen and Song (1998), construction quality, schedule, and costs are the three most 
important factors when deciding which company will win the auction. Additional factors including market conditions, payment arrangements, the number of competitors, and thirdparty stakeholders have also been identified (Ye et al. 2012). Therefore, many tender evaluation criteria have proliferated over the years, with both quantitative and multicriteria approaches being applied (Lai et al. 2004; Shen et al. 2004).

However, the main awarding criterion: the lowest price offered, is still widely used in China, as with many construction industries throughout the world (Ballesteros-Pérez et al. 2015b, 2016). As is well known, this economic awarding criterion does not guarantee that the final cost is necessarily the lowest (Wong et al. 2001). Given the highly competitive profile of China's construction market (e.g., Cheah and Chew 2005), contractor selection using the lowest price often attracts unrealistically low bids. Bidders face the temptation of relinquishing the prospect of making a reasonable profit by legitimate means in order to be awarded a contract. Once awarded, they seek to obtain a profit through later changes and claims. Therefore, such a situation often causes future problems for both the owner and the contractor when claims arise over scope, costs, quality, and schedule disagreements (e.g., Ioannou and Leu 1993; Ye et al. 2008).

\section{Construction Contractor Credit Scoring (CCCS)}

Credit scoring is the process of assigning a quantitative value to represent creditworthiness. It has become a popular theme in recent research and practice (Arya et al. 2013). The scores are based on the statistical analysis of a person's credit report and ability to repay potential loans (Arya et al. 2013). A variety of credit scoring models have been developed, 
the most common of which in financial markets is the individual credit score developed by the Fair Isaac Corporation (FICO) (Mayer et al. 2009). The FICO score has been used by many commercial banks to make loan decisions and to determine whether the borrower can be given a "prime rate" for having a satisfactory credit score. When house prices declined in the U.S. in 2008 , for instance, mortgage defaults rose sharply and were particularly concentrated among “subprime" borrowers with low FICO scores (Mayer et al. 2009).

Credit scoring construction contractors provides an important means of helping avoid poor credit-related problems such as shoddy projects, chains of defaults, and corruption. Hatush and Skitmore's (1997) Delphi interview studies, for example, found that credit status and reputation, as well as technical ability and management capability, were critical to successful contractor selection in prequalification and bidding. Similar to general credit scores at the individual and corporate level, contractor credit in the construction industry measures the willingness and likelihood of successfully completing a construction project (Liu and Zhu 2006). However, there have been only a few studies of contractor credit scores, with Liu and Zhu (2006), for example, proposing a rough set method to assess the credit of contractors; and Tserng et al. (2010) using three option-based credit models to predict construction contractor defaults.

\section{construction contractors, generates a huge demand for construction work. In recognition of the} problems associated with lowest bid tendering, the Beijing Municipal Commission Housing and Urban-Rural Development (BMCHURD) and Beijing Municipal Commission of Development and Reform (BMCDR) issued their pilot policy Quantitative Tender Assessments 
for Beijing Construction Projects, effective since the start of 2013. The change brought about by this policy was the launch of the CCCS scheme for contractors registered in Beijing and its use in later tender assessments to enhance the credibility and reputation of construction contractors and reflect the strong determination of the central government to improve the overall credit rating of the construction industry.

Of particular relevance here is an amendment incorporating $C C C S$ scores into the construction project procurement process in Beijing, which clearly envisions that "a company's market performance today will determine its market access and market share tomorrow". The policy involves $C C C S$ scores rated by the government authority and used in both tenderer selection as an essential part of the current tendering evaluation system combining economic bid $(E B)$ and technical bid $(T B)$ scores. The intense competitive nature of Beijing's construction industry means that construction contractors naturally are expected to seek a competitive advantage by improving their CCCS scores.

Similarly to the FICO formula, the calculation of $C C C S$ scores involves a complex process with assessments of organizational level information including contract information, technical progress, professional awards and corporate social responsibility. There is also project level information, with such items as general management, safety management, construction site management, quality management, contract management, HR management, and materials management, plus another 352 penalty items covering these aspects.

The launch of a new policy in China usually comprises problem identification, policy initiation, implementation, and evaluation. Typical of the China Government approach, the large-scale implementation of new policies necessarily involves evaluated pilot studies and the 
phased initiation of policy to help avoid risks and inform future policies (Swanson and Bhadwal 2009). Timely evaluation of the impact of pilot studies is important in order to alert wrong decisions, guide future policy revisions and improvements, provide alternative approaches, and gain extra support for decision-makers (Weiss 1988).

However, although the CCCS project procurement policy had the reasonable expectation that companies would perform better as a result, its actual effect on contractors the main players in the construction market - have yet to be evaluated empirically. As commented in 2000 by Economics Nobel Laureate James Heckman, micro data including individual data and individual decision models are needed to test micro policy and provide a more credible description (Heckman 2001). Therefore, this article is aimed at providing an understanding of the effects of $C C C S$ procurement by using quantitative analysis methods to analyze empirical evidence from real projects and companies in Beijing.

\section{Research Methods}

\section{Data}

Detailed information of 158 high-rise residential construction projects tendered in Beijing during 2013 and the bidders' evaluation scores were collected from the Beijing Engineering Construction Trading Information Centre (BECTIC). These comprise $85.9 \%$ of all open bid housing projects in Beijing during 2013. To investigate the effects of $C C C S$ procurement at the organizational level, the 2071 registered general construction contractors in
Beijing are analyzed, with especial focus on the 175 with $C C C S$ scores among the top $10 \%$. 
211 These 175 companies have total revenues amounting to $70 \%$ of the total construction expenditure in Beijing from 2011 to 2013. Key descriptions of the sample projects and sample

213 companies are summarized in Table 1.

\section{<Insert Table 1 here $>$}

Analyses

A twofold method of analysis is applied to both the project and organizational levels.

217 Since $C C C S$ policy aims to align a company' market performance with its market access and 218 market share, the main focus of the analyses is to estimate the extent to which a company's

$219 C C C S$ score affects its market access and prospects of winning contract auctions (Research 220 question 1), increase its company income (Research question 2), and changes in its CCCS 221 scores over time (Research question 3). To investigate these effects, quantitative analysis 222 techniques including basic descriptive statistics, principal component regression, and latent variable growth modeling are applied. These are described here in terms of competitive measurement in project bidding, and evaluating the impact at the organizational level.

\section{Competitiveness measurement in bidding}

The economic bid $(E B)$ score is determined by comparing the bid prices. Normally, the bid closest to the average bid receives the highest score. Technical bid (TB) scores are provided by five (or seven, if the project is large) industry experts according to an itemized questionnaire. The overall score of a bidder $i$ for project $j, Q_{i j}$, is calculated by multiplying 
231 the $E B, T B$, and $C C C S$ scores of bidder $i$, that is $S_{i j}^{E B}, S_{i j}^{T B}$, and $S_{i j}^{C C C S}$ respectively, by the 232 respective weights $\left(W_{j}^{E B}, W_{j}^{T B}\right.$ and $W_{j}^{C C C S}$ ) stated in the tender documents, such as:

$$
Q_{i j}=W_{j}^{E B} \cdot S_{i j}^{E B}+W_{j}^{T B} \cdot S_{i j}^{T B}+W_{j}^{C C C S} \cdot S_{i j}^{C C C S}
$$

where the CCCS weights have four levels: $5 \%, 10 \%, 15 \%$, and $20 \%$ normally depending on 235 the project size (small, medium, large, and mega) (BMCHURD and BMCDR 2012) as specified in Table 1. Therefore, firstly, a one-way ANOVA will be performed to test whether the $C C C S$ scores differ between the groups formed by all bidders, the shortlisted bidders, and the winners. the winners. For this purpose, the variable $C C C S$ competitiveness (noted as $C^{C C C S}$ ) measures the effect of $C C C S$ scores between the winner and both second best and last ranked bidder, respectively, as:

Similar statistics, including $C_{j}^{E B-1}, C_{j}^{E B-2}, C_{j}^{T B-1}$ and $C_{j}^{T B-2}$, are calculated to measure the competitiveness for $E B$ and $T B$.

Finally, considering the impact of project size, the Kruskal-Wallis test will also be applied to determine if statistics including $C_{j}^{C C C S-1}, C_{j}^{C C C S-2}, C_{j}^{E B-1}, C_{j}^{E B-2}, C_{j}^{T B-1}$ and $C_{j}^{T B-2}$ differ by project size. The Kruskal-Wallis test is a non-parametric test that compares the medians of two samples. It is also named the 'one-way ANOVA on ranks' which, unlike the latter, does not assume the residuals follow a Normal distribution. 

hypothesis (i.e., the medians of the paired differences equal zero) must be accepted or rejected

254 for each project size (small, medium, large, and mega). Again, the Wilcoxon signed-rank nonparametric test is an alternative to the paired Student's t-test when the population cannot be assumed to be Normally distributed. All the results will be presented later in the Analysis and results section.

Evaluating Impact at the Organizational Level income, as well as changes in the $C C C S$ scores over time. The former will answer the second research question, that is, if the current $C C C S$ scores determine the contractor's market access. The latter will answer the third research question, that is, borrowing Beijing's contracting authority words, if “a company's market performance today determines its market access and market share tomorrow". the emergence of CCCS scores from 2012 to 2013, that is, just before and after the implementation of the new policy. If, as proposed in the second research question, the CCCS increases corporate income, there should be a positive correlation as a result. The regression expression is presented later but contains the following variables: values of construction contracts awarded in Beijing during 2013 (Y), values of construction contracts awarded in 

equation modeling (SEM) - will be used to answer the third research question, that is, to examine the changes in $C C C S$ scores over time. SEM is a common quasi-routine data mining approach used in social science studies (Xiong et al. 2015) and LGM in particular is used to measure the changing trend of some variables over time to reveal both intra-individual and inter-individual variability (MacCallum and Austin 2000). The advantages of LGM also include the ability (a) to provide conclusions at the aggregate level; (b) to model growth over time in linear or nonlinear trajectories; and (c) to use estimated parameters for later prediction (Walker et al. 1996). Aimed at understanding the average change and individual variation in changes, the application of LGM to longitudinal data assumes that each company has a specific intercept and changing slope (Peterson et al. 2011).

used in model development. Various statistics, including Chi-square $\left(\chi^{2}\right)$, root mean square error of approximation (RMSEA), comparative fit index $(C F I)$ and the Tucker-Lewis index (TLI) will also be used to assess the model's goodness of fit, as detailed later.

\section{Analyses and Results}

Competitiveness measurement in bidding no more than seven bidders. This is verified in the sample, where this occurred in 145 out of the 158 auctions involved. In addition, there are 2071 registered general contractors in the 
294

295

296

Beijing construction market, with 175 having CCCS scores higher than 67.71 (out of 100). As shown in Table 2, companies with higher CCCS scores account for a larger proportion of selected bidders and winners.

\section{$<$ Insert Table 2 here $>$}

With median CCCS scores of 80.91 and 83.55 , the shortlisted bidders and winners are clearly higher than the 50.5 of the 2071 companies as a whole. This is confirmed by a KruskalWallis test with $p<0.001\left(\chi_{d f=2}^{2}=1364.51\right)$. Therefore, the null hypothesis is rejected, that is, the medians of all the groups' (i.e. general contractors, shortlisted bidders and winners) $C C C S$ scores are not equal. The $C C C S$ score has therefore proven its effectiveness in narrowing market access to insufficiently scored construction companies.

Next, the top of Table 3 gives the descriptions of the $E B, T B$, and $C C C S$ weights for the 158 sample auctions and related competitiveness measurement statistics.

\section{$<$ Insert Table 3 here $>$}

Kruskal-Wallis tests are firstly applied to determine if the statistics $C_{j}^{E B-1}$, $C_{j}^{E B-2}, \quad C_{j}^{T B-1}, \quad C_{j}^{T B-2}, \quad C_{j}^{C C C S-1}$, and $C_{j}^{C C C S-2}$ differ by project size. It is found that only $C_{j}^{E B-1}$ (with $\left.p=0.028\right), C_{j}^{E B-2}$ (with $p=0.0012$ ) and $C_{j}^{C C C S-2}$ (with $p=0.039$ ) barely reject the null hypothesis (for $\alpha=0.001$, despite still below 0.05 ). This means the latter three statistics need to be analyzed by project size (as in Table 3 ).

Wilcoxon signed rank tests are then used to test $C_{j}^{E B-1}, C_{j}^{E B-2}$, and $C_{j}^{C C C S-2}$ by different project size groups, as well as the overall $C_{j}^{C C C S-1}, C_{j}^{T B-1}$, and $C_{j}^{T B-2}$ statistics. 
314 With only two cases $(N=2)$, the data subset of small projects is not used for the Wilcoxon 315 test. The results from Table 3 suggest that (a) the median of $C_{j}^{C C C S-1}$ is not significantly

317 different from zero $(p=0.393)$; (b) the median of $C_{j}^{C C C S-2}$ between the medium size projects 318 is not significantly different from zero $(p=0.470)$ either, but medians of $C_{j}^{C C C S-2}$ between 319 the large and mega projects are significantly larger than zero; and (c) despite differences 320 across project size groups, the medians of $C_{j}^{E B-1}, C_{j}^{E B-2}, C_{j}^{T B-1}$ and $C_{j}^{T B-2}$ are significantly 321 larger than zero. This indicates that few bidders win a contract solely because of their higher $C C C S$ scores. However, bidders with low $C C C S$ scores are unlikely to win large and mega projects, meeting the expectations of the policy (that $C C C S$ scores are important in tender assessment). On the other hand, and as probably expected, $E B$ and $T B$, being always significant, have a larger impact on the final contract award.

\section{Evaluating Impact at the Organizational Level}

Based on results of the correlation analyses, it is reasonable to try to predict the corporate income of company $i$ in 2013 ( $Y$ ) from the previous records of the company in 2012 $\left(X_{2}\right)$ and its $C C C S$ scores $\left(X_{1}\right)$ via the equation $Y=a+b_{1} X_{1}+b_{2} * X_{2}$. proportion larger than 0.5 , indicating that collinearity is likely to have a distorting effect. To avoid this bias, principal component regression is used to obtain the corrected coefficients (see 
with $R^{2}=0.65$. This indicates that corporate good behavior may be tacit knowledge when clients were selecting contractors before the enforcement of the new policy.

Considering that the overall corporate income increase for contractors with the highest CCCS scores from 2012 to 2013 is approximately the difference between $\sum_{i=1}^{175} Y=\mathrm{CNY} 251.53$ billion and $\sum_{i=1}^{175} X_{2}=\mathrm{CNY} 198.91$ billion (that is, CNY 52.62 billion) the effects of the CCCS scores seem to be clearly influential. This is confirmed by the significant positive correlation of $X_{1}$ with the $C C C S$ scores $(p<0.001)$. However, the $X_{2}$ slope is not significant $(p=0.224)$. These results indicate that the CCCS scores are likely to become an independent factor contributing to corporate income, different from the factors describing previous corporate incomes.

Finally, repeated measures of individual contractors' $C C C S$ scores are used across five periods: the middle of 2013 , the end of 2013, the middle of 2014, the end of 2014, and the middle of 2015, named CCCS13Mid, CCCS13End, CCCS14Mid, CCCS14End, and CCCS15Mid respectively. Table 4 summarizes descriptions of the CCCS scores at these points and the correlations of 169 of the $175(96.6 \%)$ contractors after deleting cases with missing data. It is also worth highlighting that normality of the data is an important assumption when applying the default maximum likelihood estimation method in LGM. For this purpose, it is generally sufficient for the sample skewness and excess kurtosis range to be within $[-1,1]$ (Xiong et al. 2015). As presented in Table 4, this is the case for the five variables. 
21.0 software. The LGM goodness of fit, as described earlier, requires the following conditions

to be checked (King and McInerney 2014): Chi-square ( $\chi^{2}$ preferably with $p<0.05$, but at least with $p<0.10)$, the root mean square error of approximation $(R M S E A<0.08)$, comparative fit index $(C F I>0.9)$, and the Tucker-Lewis index $(T L I>0.9)$. All conditions are met, with $\chi_{(d f=4)}^{2}=7.868(p=0.097), C F I=0.997, T L I=0.992$, and $R M S E A=0.076$, suggesting a sufficient model fit. With this verification, it is then acceptable to use the proposed LGM to describe the changes in the companies' CCCS scores over time. Coefficients of determination $\left(R^{2}\right)$ ranging from 0.740 to 0.934 of the five variables also indicate that a satisfactory amount of variance is explained.

\section{$<$ Insert Figure 1 here $>$}

Finally, according to the results shown in Table 5, the average initial CCCS score of the companies in the middle of 2013 was 80.124 (46.748 variance), with an average slope of -1.079 (5.987 variance). After conducting a standard transformation, the distribution of the slope values indicate that $32.96 \%$ of the companies have a positive slope (increasing $C C C S$ trend) while $67.04 \%$ companies have a negative slope (i.e. decreasing CCCS trend) over the five time periods. The significant covariance $(p=0.05 \approx \alpha)$ between the intercept and slope indicates that companies with higher intercepts have larger slopes on average. 
The theoretical and practical implications concerning the impact of Beijing's new

378 policy are discussed in the following subsections.

Are CCCS Scores Important for Winning a Contract?

The CCCS scheme was launched by the government to monitor and enhance the performance of contractors. The practice of incorporating the CCCS scores into the bid evaluation process, as required in Beijing's new procurement policy, is intended to push companies into increasing their corporate credit ratings to avoid being disadvantaged against their competitors. As presented in the analysis section, the two aspects linking policy and projects are particularly explored in terms of tender access and bidding competitiveness. For access, it is found that companies with higher $C C C S$ scores are most likely to be shortlisted as bidders. This is supported by previous studies of prequalification criteria, where corporate credit and reputation are held to be a major concern (Hatush and Skitmore 1997; Shen and Song 1998; Shen et al. 2004).

The tender assessment of Beijing projects is further evaluated to gauge the impact of $C C C S$ scores on bidder competitiveness, indicating that contractors with the lowest CCCS scores are unlikely to be awarded contracts for large and mega projects, while the competition between the winner and the second best candidate are mainly determined by price and technical soundness. Therefore, this new policy should eliminate unreliable candidates and make the competition among reliable candidates focus on preparing for projects. This indicates that the 
weights allocated to CCCS scores by BMCHURD \& BMCDR (2012) for large and mega projects are appropriate. However, the insignificant competitiveness difference in $C C C S$ scores

399 has also been found in medium size projects. This could be the consequence of too small 400 weights being allocated to the $C C C S$ scores for this type of project. research (Mayer et al. 2009) and the appropriate sizing of these weights should avoid this. The $C C C S$ for large and mega projects were important but not overemphasized, while the $C C C S$ for medium projects should probably have to be revised if the CCCS component wants to be minimally emphasized.

\section{What is the Impact of CCCS Scores on Corporate Income?}

In addition to the examination of $C C C S$ scores at the project level, an exploration at the organizational level is also conducted. Acknowledging the importance of corporate credit in contractor selection, the scheme makes quantitatively explicit what was originally a tacit rule: " a company's market performance today will determine its market access and market share tomorrow". Correlation and regression analyses indicate that the newly emerged $C C C S$ scores contributed to corporate income change between 2012 and 2013. The large coefficient of the $C C C S$ in Equation (4) indicates that corporate credit significantly affects corporate income, as only highly $C C C S$ scored bidders are being shortlisted and eventually awarded contracts. 
to answer this question are not generally published by the Chinese government, nor are they easily shared by the contractors. However, items describing satisfactory past execution performance are assessed when updating the contractors' CCCS scores. This means that, to remain competitive and being shortlisted for future tenders, a contractor needs to perform consistently according to expectations. This safeguard is another point in favor of the credit scoring policy.

Therefore, although well known for its poor quality and low trust inter-organizational relationships, the construction industry is becoming highly demanding of trust-based collaboration and higher ethical standards (Wood et al. 2002). The analysis results show that appropriate ethical standards emphasizing corporate credit have been achieved over time, despite the prevalent lack of trust and credit in China after its sudden economic transformation. This is also consistent with Xiong et al.'s (2016) longitudinal study finding a virtuous nexus between construction enterprises financial performance and their corporate social responsibility in China. Additionally, it is already rooted in China's ubiquitous Confucius culture of "using proper ways to riches and honor" and "seeing profits as well as rightness", as in the Analects.

\section{How CCCS Scores Change Over Time?}

In many cases, the instruments of public policy are not neutral and unexpected effects are common in their implementation. A public policy may incentivize some and penalize others (Lascoumes and Le Gales 2007). Therefore, the different effects of the new project 
procurement policy need to be considered carefully. The policy takes for granted that it can improve corporate credit since, as reported in the mass media, it is instrumental in determining corporate income (Wang and Yu 2012). However, the results of the latent growth model do not support this assumption. This might be attributed to the short observation period and inconsistency of the selected contractors. In the latter case, it is found that contractors with higher initial $C C C S$ scores always enjoy faster increases in their CCCS scores, while contractors with lower initial $C C C S$ scores may face a slower increase or faster decrease in their $C C C S$ scores.

In the long run, these companies may face a polarized situation. One the one hand, contractors with high corporate credit faces the virtuous nexus between corporate social performance and financial performance. Companies with better financial performance can allocate more resources (defined as "slack resources") to socially responsible activities, which ultimately increase financial performance for gaining even more competitive advantage (Waddock and Graves 1997; Xiong et al. 2016). Companies with lower corporate credit, on the other hand, can fall into Porter and Kramer's (2011) "vicious circle" between business and society. Therefore, a major concern is how to inspire companies with lower corporate credit to change and improve their future performance.

\section{Conclusions}

Trustworthiness and corruption have long been major causes of concern in the Chinese 
460 (CCCS) scheme in Beijing is intended to address these problems. The scheme aims to evaluate 461 the compliance and integrity of firms registered as contractors in the construction market. 462 However, it is unclear if and how well this scheme is working, as well as its side effects on 463 local contractors.

Through the procurement of 158 building projects in Beijing, involving 2071 local general contractors, this paper analyzes the scheme's effects on the contractors' contractors' $C C C S$ scores are important for their selection for bidding and being awarded contracts for large and mega projects; (2) the CCCS scores have a generally positive effect on corporate financial income; and (3) unexpectedly, the policy does not increase the CCCS of companies. The changing trend in $C C C S$ scores is also associated with their initial values, since the scores of higher $C C C S$ scoring companies increase faster on average than other companies.

The important implications for project management and project procurement are that the incorporation of explicit $C C C S$ scores is useful for selecting more reliable contractors. The implementation of this new policy is expected to help in creating shared value by maximizing economic and social benefits for both contractors and government. However, construction companies need time to recognize the role of the CCCS scores in awarding contracts and take action to seek competitive advantage by improving their $C C C S$ scores over time. Considering the high level of competition in the Chinese construction industry, it is reasonable to expect that many companies with initially low CCCS scores will try to secure more contracts by increasing their corporate credit. 

general contractors between 2013 and 2015. Future data collection may require a different approach depending on the questions to be answered. For example, further research is needed to investigate the visibility of contractor credit scores and risks such as credit score manipulation. The visibility of contractor credit scores could lower the information asymmetry between clients and contractors, improve public supervision, and improve the ethical behavior of contractors in the face of social pressure and competitive forces. also not be ignored. For example, the $C C C S$ weight also needs to be appropriate. If the weight is too low, corporate credit does not affect the contract award, as was the case for medium size projects. On the other hand, if the weight is too high, corporate credit may be overemphasized, so that a contractor could earn a project by its reputation rather than by sound preparation for a specific project. Finally, the overemphasis of corporate credit may lead to the manipulation of credit scoring. For the implementation phase, it is important that contractors have sufficient time and resources to make changes to improve their performance, and further research is needed to ensure that this is fully taken into account. The outcomes of this study also have particular implications for many other developing countries struggling with corruption and pursuing higher standards in public procurement, in providing a head start to contractors whose ethical behavior and past performance have been satisfactory. 


\section{Acknowledgement}

The first author was financially supported by a QUT HDR Sponsorship from the research project "Hosting, Maintenance and Further Development of the BER - Cost Analysis Model" funded by the Commonwealth of Australia represented by the Department of Education.

\section{Data Availability}

Data generated or analyzed during the study are available from the corresponding author by request.

\section{References}

Arya, S., Eckel, C., and Wichman, C. (2013). "Anatomy of the credit score.” Journal of Economic Behavior and Organization, 95, 175-185.

Ballesteros-Pérez, P., Skitmore, M., Pellicer, E., and González-Cruz, M.C. (2015a) "Scoring rules and abnormally low bids criteria in construction tenders: a taxonomic review." Construction Management and Economics, 33, 259-278.

Ballesteros-Pérez, P., Skitmore, M., Das, R., del Campo-Hitschfeld, M.L. (2015b). "Quick abnormal-bid-detection method for construction contract auctions." Journal of Construction Engineering and Management 141(7), 4015010.

Ballesteros-Pérez, P., Skitmore, M., Pellicer, E., Zhang, X. (2015b). "Scoring rules and competitive behavior in best-value construction auctions." Journal of Construction Engineering and Management 142(9), 04016035.

Bekkers, V., Edelenbos, J., and Steijn, B. (Eds.). (2011). "Innovation in the public sector." New York: Palgrave Macmillan.

Beijing Municipal Commission Housing and Urban-Rural Development (BMCHURD) and Beijing Municipal Commission of Development and Reform (BMCDR) (2012). "Quantitative tender assessments for Beijing construction projects" 
〈http://www.bjjs.gov.cn/bjjs/xxgk/qtwj/gcjsltz/353491/index.shtml〉 (July 17, 2018) (in Chinese).

China Statistics Bureau (CSB). (2013). "2012 survey report of Chinese peasant workers", 〈http://www.stats.gov.cn/tjsj/zxfb/201305/t20130527_12978.html〉 (July 17, 2018) (in Chinese).

Cheah, C. Y., and Chew, D. A. (2005). "Dynamics of strategic management in the Chinese construction industry." Management Decision, 43, 551-567.

Drew, D. S., and Skitmore, R. M. (1992). "Competitiveness in bidding: a consultant's perspective." Construction Management and Economics, 10, 227-247.

Fenn, P., Lowe, D., and Speck, C. (1997). "Conflict and dispute in construction." Construction Management and Economics, 15, 513-518.

Hatush, Z., and Skitmore, M. (1997). "Criteria for contractor selection.” Construction Management and Economics, 15, 19-38.

Hatush, Z., and Skitmore, M. (1998). "Contractor selection using multicriteria utility theory: an additive model." Building and Environment, 33, 105-115.

Heckman, J. J. (2001). "Micro data, heterogeneity, and the evaluation of public policy: Nobel lecture." Journal of Political Economy, 109(4), 673-748.

Ioannou, P. G., and Awwad, R. E. (2010). "Below-average bidding method.” Journal of Construction Engineering and Management, 136(9), 936-946.

Ioannou, P. G., and Leu, S. S. (1993). "Average-bid method-competitive bidding strategy." Journal of Construction Engineering and Management, 119(1), 131-147.

King, R. B., and McInerney, D. M. (2014). "Mapping changes in students' English and math self-concepts: A latent growth model study." Educational Psychology, 34, 581-597.

Lai, K. K., Liu, S. L., and Wang, S. Y. (2004). "A method used for evaluating bids in the Chinese construction industry." International Journal of Project Management, 22, 193201.

Lascoumes, P., and Le Gales, P. (2007). "Introduction: understanding public policy through its instruments - from the nature of instruments to the sociology of public policy instrumentation." Governance, 20(1), 1-21.

Lin, W. L. (2010), "Corporate social responsibility in China: Window dressing or structural change.” Berkeley Journal of International Law, 28(1), 64-100.

Liu, D., Xu, W., Li, H., Zhang, W., and Wang, W. (2011). "Moral hazard and adverse selection in Chinese construction tender market: A case of Wenchuan earthquake." Disaster Prevention and Management, 20(4), 363 - 377. 
Liu, G., and Zhu, Y. (2006). "Credit assessment of contractors: a rough set method.” Tsinghua Science and Technology, 11(3), 357-362.

Lu, W., and Tam, V. W. Y. (2013). "Construction waste management policies and their effectiveness in Hong Kong: A longitudinal review.” Renewable and Sustainable Energy Reviews, 23, 214-223.

MacCallum, R. C., and Austin, J. T. (2000). "Applications of structural equation modeling in psychological research.” Annual Review of Psychology, 51(1), 201-226.

Mayer, C., Pence, K., and Sherlund, S. M. (2009). "The rise in mortgage defaults." The Journal of Economic Perspectives, 23(1), 27-50.

Ministry of Construction (MOC). (2015). "Regulation on qualification management for construction enterprises, China." (http://www.mohurd.gov.cn/fgjs/jsbgz/201502/t20150206_220284.html) (17 July 2018) (in Chinese).

Ministry of Finance (MOF). (2004). "Regulation on the administration of tenders and invitations to bid for goods and services of government procurement." 〈http://www.mof.gov.cn/zhengwuxinxi/caizhengwengao/caizhengbuwengao2004/caizheng buwengao20047/200805/t20080519_20232.html (July 17, 2018) (in Chinese).

Nakamura, R. T. (1987). "The textbook policy process and implementation research.” Review of Policy Research, 7(1), 142-154.

National Development and Reform Commission (NDRC) (2003). "Regulations on the administration on the tenders and invitations to bid for construction project." (http://www.gyfg.gov.cn/article-21-13359.aspx) (July 17, 2018) (in Chinese).

Nwabuzor, A. (2005). "Corruption and development: new initiatives in economic openness and strengthened rule of law." Journal of Business Ethics, 59(1-2), 121-138.

Peterson, S. J., Luthans, F., Avolio, B. J., Walumbwa, F. O., and Zhang, Z. (2011). "Psychological capital and employee performance: A latent growth modeling approach." Personnel Psychology, 64(2), 427-450.

Porter, M. E., and Kramer, M. R. (2011). “Creating shared value.” Harvard Business Review, 89 (1/2), 62-77.

Preuss, L. (2009). “Addressing sustainable development through public procurement: the case of local government." Supply Chain Management: An International Journal, 14(3), 213-223.

Raymond, J. (2008). “Benchmarking in public procurement.” Benchmarking: An International Journal, 15(6), 782-793.

Shen, L., and Song, W. (1998). "Competitive tendering practice in Chinese construction." Journal of Construction Engineering and Management, 124(2), 155-161. 
Shen, L. Y., Li, Q. M., Drew, D., and Shen, Q. P. (2004). "Awarding construction contracts on multicriteria basis in China." Journal of Construction Engineering and Management, 130, 385-393.

Shen, L. Y., and Tam, V. W. Y. (2002). "Implementation of environmental management in the Hong Kong construction industry." International Journal of Project Management, 20(7), 535-543.

Swanson, D., and Bhadwal, S. (2009). "Creating adaptive policies: A guide for policymaking in an uncertain world." IDRC.

Tam, O. K. (2002). "Ethical issues in the evolution of corporate governance in China." Journal of Business Ethics, 37, 303-320.

Tow, D., and Loosemore, M. (2009). "Corporate ethics in the construction and engineering industry." Journal of Legal Affairs and Dispute Resolution in Engineering and Construction, 1(3), 122-129.

Tserng, H. P., Liao, H. H., Tsai, L. K., and Chen, P. C. (2010). "Predicting construction contractor default with option-based credit models-Models' performance and comparison with financial ratio models." Journal of Construction Engineering and Management, 137(6), 412-420.

Waddock, S. A., and Graves, S. B. (1997). "The corporate social performance-financial performance link.” Strategic Management Journal, 18, 303-319.

Walker, A. J., Acock, A. C., Bowman, S. R., and Li, F.. (1996). "Amount of care given and caregiving satisfaction: A latent growth curve analysis." The Journals of Gerontology Series B: Psychological Sciences and Social Sciences, 51, 130-142.

Walker, H., and Preuss, L. (2008). "Fostering sustainability through sourcing from small businesses: public sector perspectives." Journal of Cleaner Production, 16(15), 16001609.

Wang, Z., and Yu, Z. (2012). "Trading partners, traded products and firm performances of China's exporter-importers: Does processing trade make a difference?" The World Economy, 35(12), 1795-1824.

Weiss, C. H. (1988). "Evaluation for decisions: Is anybody there? Does anybody care?" Evaluation Practice, 9, 5-19.

Wong, C. H., Holt, G. D., and Harris, P. (2001). "Multi-criteria selection or lowest price? Investigation of UK construction clients' tender evaluation preferences." Engineering Construction and Architectural Management, 8, 257-271.

Wood, G., McDermott, P., and Swan, W. (2002). "The ethical benefits of trust-based partnering: the example of the construction industry." Business Ethics: A European Review, 11(1), 4-13. 
634 Xiao, J. (2014). "Corruption pattern analyses of public project and preliminary estimate in 635 China." Observation and Ponderation, 2014(8), 53-62.

636 Xiong, B., Lu, W., Skitmore, M., Chau, K. W., and Ye, M. (2016). "Virtuous nexus between 637 corporate social performance and financial performance: a study of construction 638 enterprises in China." Journal of Cleaner Production, 129, 223-233.

639 Xiong, B., Skitmore, M., and Xia, B. (2015). "A critical review of structural equation 640 modeling applications in construction research." Automation in Construction, 49, 59-70.

641 Ye, K., Jiang, W., and Shen, L. (2008). "Project competition intensity (PCI) in the 642 construction market: a case study in China." Construction Management and Economics, $643 \quad 26,463-470$.

644 Ye, K., Li, B., and Shen, L. (2012). "Key factors considered in compiling tender prices for 645 China's public works projects." Journal of Management in Engineering, 29, 206-215. 
Table 1. Data summary of the sample projects and companies

\begin{tabular}{ccccccc}
\hline Sample & Group & Size $\left(10^{6} \mathrm{CNY}\right)$ & Frequency & $\%$ & Mean value & St. Dev. \\
\hline \multirow{4}{*}{158} & Small & Less than 30 & 2 & 1.3 & 19.24 & 1.79 \\
Projects & Medium & $30-100$ & 56 & 35.4 & 60.94 & 19.26 \\
& Large & $100-300$ & 72 & 45.6 & 169.91 & 55.61 \\
& Mega & Greater than 300 & 28 & 17.7 & 442.28 & 180.4 \\
& & Total & 158 & 100 & 177.65 & 157.54 \\
\hline \multirow{4}{*}{175} & Grades & Excellent & 63 & 36 & $/$ & $/$ \\
contractors & & Grade 1 & 105 & 60 & $/$ & $/$ \\
\cline { 3 - 7 } & Avg. & Grade 2 & 7 & 4 & $/$ & $/$ \\
\cline { 3 - 6 } & income & Less than 100 & 8 & 4.57 & 74.61 & 31.11 \\
& 2011-13 & Greater than 1000 & 43 & 24.57 & 2394.85 & 1641.69 \\
& & Total & 175 & 100 & 924.19 & 1186.12 \\
\hline
\end{tabular}

648 Note: 1 USD $=6.69$ CNY on 17 July 2018. 
Table 2. $C C C S$ scores related to market access and market share at the project level.

\begin{tabular}{lccc}
\hline CCCS scores & 2071 companies & $\begin{array}{c}782 \text { shortlisted bidders } \\
\text { in } 158 \text { contracts }\end{array}$ & $\begin{array}{c}\text { Winners of } 158 \\
\text { contracts }\end{array}$ \\
\hline Range & $33.00-96.71$ & $44.50-96.71$ & $46.50-96.71$ \\
Mean $(95 \% \mathrm{CI})$ & $54.75(54.37,55.15)$ & $78.40(77.48,79.28)$ & $80.50(78.43,82.47)$ \\
SD $(95 \% \mathrm{CI})$ & $9.14(8.634,9.655)$ & $12.66(12.064,13.20)$ & $13.09(11.64,14.31)$ \\
Mode & 50 & 50.50 & 73.17 \\
Median & 50.5 & 80.91 & 83.55 \\
$>67.71$ & $175(8.45 \%)$ & $625(79.95 \%)$ & $134(84.81 \%)$ \\
$<=67.71$ & $1896(91.55 \%)$ & $157(20.05 \%)$ & $24(15.19 \%)$ \\
\hline
\end{tabular}

650 Note: 782 shortlisted bidders and 158 winners are calculated by direct count, that is, the same 651 company may have been shortlisted or winner several times. 
652 Table 3. Descriptive statistics and competitiveness measurement statistics of project weights

\begin{tabular}{|c|c|c|c|c|c|c|}
\hline Type & $N$ & Min & Max & Mean & St. Dev. & $\begin{array}{l}\text { Significance of } \\
\text { Wilcoxon } \\
\text { signed rank tests }\end{array}$ \\
\hline$E B$ weight & 158 & 0.48 & 0.90 & 0.537 & 0.056 & l \\
\hline$T B$ weight & 158 & 0.00 & 0.90 & 0.330 & 0.053 & / \\
\hline$C C C S$ weight & 158 & 0.05 & 0.20 & 0.132 & 0.029 & l \\
\hline$C_{j}^{E B-1}$ & 158 & -1.490 & 9.000 & 3.919 & 2.164 & / \\
\hline small & 2 & 6.000 & 6.330 & 6.167 & 0.235 & - \\
\hline medium & 56 & -1.490 & 9.000 & 4.218 & 2.100 & $* * *$ \\
\hline large & 73 & -6.550 & 5.950 & 1.114 & 2.220 & $* * *$ \\
\hline mega & 27 & 0.000 & 7.650 & 3.241 & 2.086 & $* * *$ \\
\hline$C_{j}^{E B-2}$ & 158 & -2.040 & 20.400 & 6.559 & 4.288 & / \\
\hline small & 2 & 6.000 & 6.330 & 6.167 & 0.235 & - \\
\hline medium & 56 & -1.490 & 9.000 & 4.218 & 2.100 & $* * *$ \\
\hline large & 73 & -2.040 & 20.400 & 5.904 & 3.919 & $* * *$ \\
\hline mega & 27 & 0.000 & 7.650 & 3.241 & 2.086 & $* * *$ \\
\hline$C_{j}^{T B-1}$ & 158 & -4.330 & 14.400 & 4.358 & 2.400 & $* * *$ \\
\hline$C_{j}^{T B-2}$ & 158 & -3.170 & 14.000 & 5.455 & 2.610 & $* * *$ \\
\hline$C_{j}^{C C C S-1}$ & 158 & -5.610 & 4.900 & 0.115 & 1.788 & 0.393 \\
\hline$C_{j}^{C C C S-2}$ & 158 & -6.550 & 8.830 & 0.925 & 2.376 & l \\
\hline small & 2 & -2.700 & -0.390 & -1.543 & 1.630 & l \\
\hline medium & 56 & -4.130 & 5.990 & 0.138 & 1.817 & 0.470 \\
\hline large & 73 & -6.550 & 5.950 & 1.114 & 2.220 & $* * *$ \\
\hline mega & 27 & -5.190 & 8.830 & 2.230 & 3.113 & $* * *$ \\
\hline
\end{tabular}

653 Note: $* * *$ indicates significant with $p<0.001$. "/" indicates that the statistic was not submitted 654 to the Wilcoxon signed rank test. "_." indicates that the statistic was not submitted to the 655 Wilcoxon signed rank test because of insufficient sample size. 
656 Table 4. Descriptive statistics and correlations for corporate credit scores during 2013-2015

\begin{tabular}{ccccccccc}
\hline \multirow{2}{*}{ Variables } & \multirow{2}{*}{ Mean } & St. & \multirow{2}{*}{ Skewness } & Kurtosis & \multicolumn{5}{c}{ Correlation } \\
\cline { 6 - 9 } & & Dev. & & & 1 & 2 & 3 & 4 \\
\hline 1.CCCS13Mid & 79.981 & 7.685 & 0.353 & -0.786 & & & & \\
2. CCCS13End & 79.840 & 8.631 & -0.189 & 0.151 & 0.919 & & & \\
3. CCCS14Mid & 79.016 & 9.692 & -0.215 & -0.591 & 0.859 & 0.862 & & \\
4. CCCS14End & 78.636 & 9.709 & -0.362 & -0.67 & 0.789 & 0.818 & 0.882 & \\
5. CCCS15Mid & 77.505 & 10.803 & -0.502 & -0.361 & 0.740 & 0.773 & 0.828 & 0.934 \\
\hline
\end{tabular}

657 Note: $N=169$, all correlations are significant with $p<0.001$. 
Table 5. LGM parameter estimates

\begin{tabular}{ccccc}
\hline Variables & $\begin{array}{c}\text { Estimate } \\
(\mathrm{E})\end{array}$ & $\begin{array}{c}\text { Standard Error } \\
(\mathrm{SE})\end{array}$ & $\begin{array}{c}\text { Crit. Ratio } \\
(\mathrm{CR}=\mathrm{E} / \mathrm{SE})\end{array}$ & $p$-value \\
\hline CCCS Intercept & 80.124 & 0.582 & 137.613 & $* * *$ \\
CCCS Slope & -1.079 & 0.271 & -3.976 & $* * *$ \\
Intercept-slope Covariance & 7.917 & 4.035 & 1.962 & 0.05 \\
\hline
\end{tabular}

Note: $* * *$ indicates significant with $p<0.001$. 


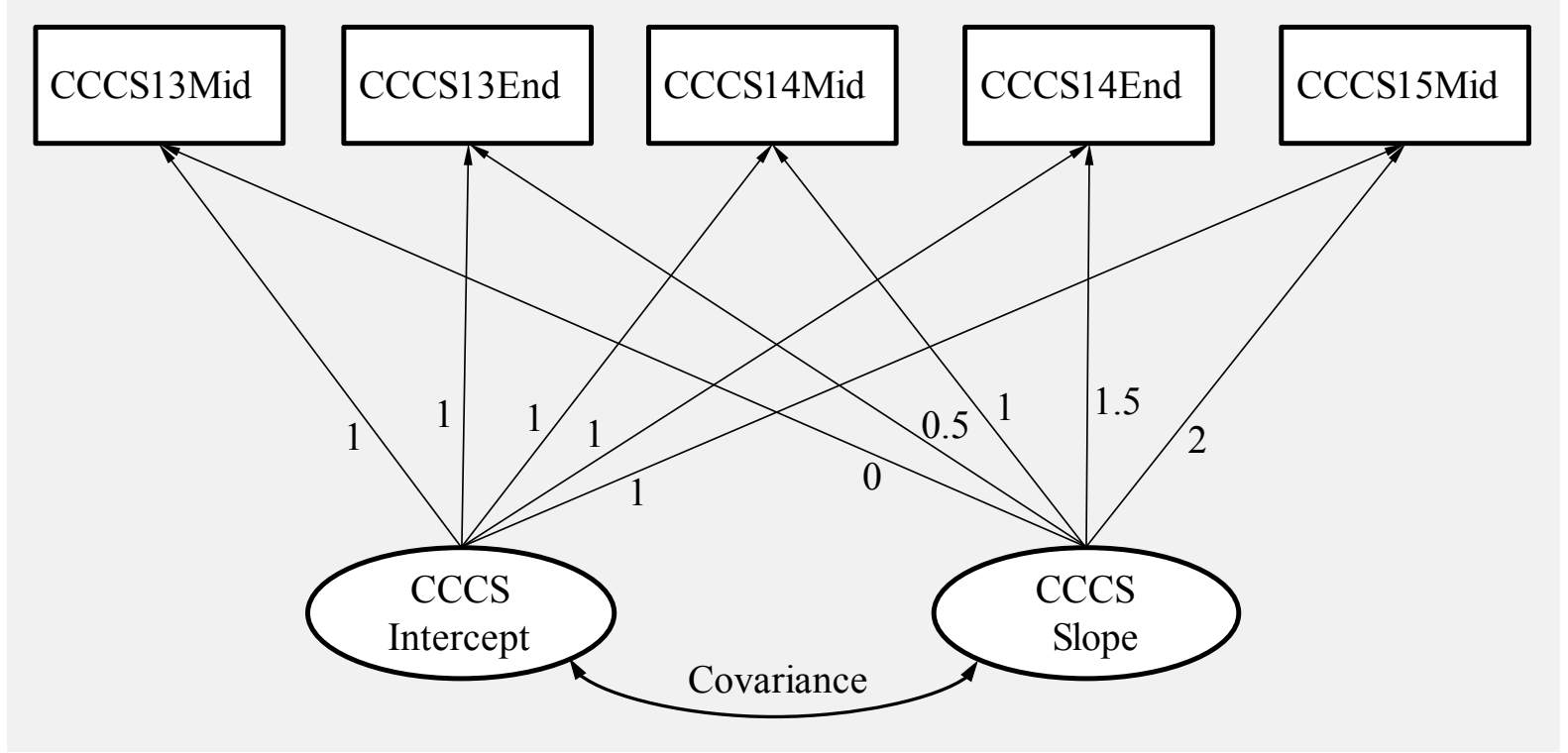

Fig. 1. Latent Growth Model measuring CCCS scores variations over time

(Numbers on the arrows are proposed loadings, for example CCCS2013End $=1 *$ CCCSintercept $+0.5 *$ CCCSslope + error $)$ 